\title{
CRASSULACEAN ACID METABOLISM IN THREE SPECIES OF THE $C_{4}$ GENUS PORTULACA
}

\author{
ANTHONY A. KRAYBILL' AND CRAIG E. MARTIN
}

Department of Botany, University of Kansas, Lawrence, Kansas 66045-2106

\begin{abstract}
The putative existence of Crassulacean acid metabolism was investigated in three succulent species of the $\mathrm{C}_{4}$ genus Portulaca: $P$. grandiflora (a widely cultivated species), $P$. oleracea (a cosmopolitan weed), and $P$. mundula (found on rock outcrops throughout the southwestern United States). Patterns of diurnal conductance and $\mathrm{CO}_{2}$ exchange, as well as diurnal tissue malic acid fluctuations, were measured in plants under well-watered and drought-stressed conditions. Net $\mathrm{CO}_{2}$ uptake in both treatments occurred only during the day, although small amounts of nighttime $\mathrm{CO}_{2}$ uptake occurred in a few individuals. Stomatal conductances in well-watered and drought-stressed $P$. mundula and droughtstressed $P$. oleracea were higher during the night than during the day, though these higher conductances were generally not accompanied by net $\mathrm{CO}_{2}$ assimilation. No significant diurnal malic acid fluctuations occurred under well-watered conditions in any species; however, under drought stress, significant diurnal malic acid fluctuations occurred in the three species. The primary source of carbon for nocturnal malic acid production is presumed to be respiratory $\mathrm{CO}_{2}$, as occurs in $\mathrm{C}_{3}$ plants that undergo CAM-cycling. This study confirms past reports of CAM acid fluctuations in $P$. grandiflora and $P$. oleracea and marks the first report of CAM activity in $P$. mundula.
\end{abstract}

\section{Introduction}

The $\mathrm{C}_{4}$ photosynthetic pathway is distinguished from the $\mathrm{C}_{3}$ pathway by the involvement of phosphoenolpyruvate (PEP) carboxylase in the initial fixation of atmospheric $\mathrm{CO}_{2}$, resulting in the production of four-carbon organic acids (Black 1973; Edwards and Walker 1983). In addition, leaves of $\mathrm{C}_{4}$ plants display the distinctive Kranz anatomy, wherein mesophyll and bundle sheath cells are different in appearance and function. This combination of anatomical and biochemical features allows a reduction of photorespiration and, consequently, maintenance of net $\mathrm{CO}_{2}$ fixation even under stressful conditions. Plants that utilize Crassulacean acid metabolism (CAM) also employ PEP carboxylase for the initial fixation of atmospheric $\mathrm{CO}_{2}$, but this process occurs at night, when water loss is minimal (Kluge and Ting 1978; Winter 1985). During the day, the stomata of CAM plants are closed, resulting in very high diurnal water-use efficiencies. A fundamental difference between $\mathrm{C}_{4}$ and CAM is that initial $\mathrm{CO}_{2}$ fixation via PEP carboxylase is separated from the subsequent reduction of $\mathrm{CO}_{2}$ via Rubisco spatially in $\mathrm{C}_{4}$ plants while in CAM plants the separation is temporal.

Although the photosynthetic pathway of most plants can be categorized as $\mathrm{C}_{3}, \mathrm{C}_{4}$, or CAM, numerous species combine aspects of two pathways (Ehleringer and Monson 1993). For example, some " $\mathrm{C}_{3}-\mathrm{C}_{4}$ intermediates" have anatomical and biochemical features intermediate between those of $\mathrm{C}_{3}$ and $\mathrm{C}_{4}$ species. Combinations at the organ level occur as well, including species with CAM stems and $\mathrm{C}_{3}$ leaves (Osmond et al. 1982). Furthermore, a few species exhibit seasonal switching between the $\mathrm{C}_{3}$ and CAM pathways (Lüttge 1993). Finally, an increasing number of species has

\footnotetext{
'Author for correspondence and reprints; present address: Department of Botany, University of California, Davis, California 956168537.

Manuscript received February 1995; revised manuscript received August 1995.
}

been found to exhibit "CAM-cycling" (Ting 1985; Martin 1995). These plants exhibit $C_{3}$ gas exchange patterns but show CAM-like diurnal acid fluctuations. As stomata are closed at night, respiration is presumably the source of $\mathrm{CO}_{2}$ during nocturnal malic acid formation. Whether CAM-cycling directly benefits a plant is unclear. Several hypotheses have been posed, including a possible increase in water conservation (Martin et al. 1988; Harris and Martin 1991) and a potential reduction of photo-inhibition (Osmond et al. 1980; Osmond 1982). Accumulating evidence, however, suggests that CAM-cycling may simply be a precursor to "CAM-idling" and may not directly benefit the plant (Rayder and Ting 1981; Sipes and Ting 1985; Martin 1995). Many plants that exhibit CAM or CAMcycling when well-watered undergo CAM-idling under severe drought stress, during which CAM acid fluctuations occur despite 24-h stomatal closure. Presumably, by maintaining metabolic activity through the fixation of respiratory $\mathrm{CO}_{2}$, these plants may resume uptake of atmospheric $\mathrm{CO}_{2}$ more rapidly upon rehydration.

Because $\mathrm{C}_{4}$ and CAM plants exhibit nearly identical biochemistry, the existence of $\mathrm{C}_{4}$-CAM intermediates is not unexpected. There are only a few, scattered reports of such plants, however, all in the genus Portulaca. Under artificial conditions, Koch and Kennedy (1980) found that a short photoperiod $(8 \mathrm{~h})$ induced diurnal acid fluctuations indicative of CAM in the $\mathrm{C}_{4}$ species Portulaca oleracea. Drought-stressed plants exhibited CAM acid fluctuations as well, albeit at reduced levels. On the other hand, subsequent fieldwork by the same authors indicated that drought-stressed individuals under long photoperiods $(13 \mathrm{~h})$ showed the greatest degree of CAM activity (Koch and Kennedy 1982). Ku et al. (1981) measured greater diurnal acid fluctuations in well-watered plants of Portulaca grandiflora than in drought-stressed individuals. Finally, in a recent survey of CAM in the family Portulacaceae, Guralnick and Jackson (1993) reported diurnal acid fluctuations in several genera including the $\mathrm{C}_{4}$ genus 
Portulaca. Several studies of Portulaca species, however, either found no evidence of CAM activity or reported peculiarities in the $\mathrm{C}_{4}$ pathway. In a survey of succulent species in North Carolina, Martin et al. (1982) found no diurnal acid fluctuations in either $P$. oleracea or Portulaca pilosa (note that Matthews and Levins $[1985 a, 1985 b$ ] treat $P$. pilosa as Portulaca mundula). Also, results of pulse-chase experiments with $\mathrm{K}$-stressed plants of $P$. oleracea by Karadge (1986) indicated $\mathbf{C}_{3}$ photosynthesis. Finally, Fathi and Schnarrenberger (1990) found that the NADP-malic enzyme of $P$. grandiflora displayed an immunochemical cross-reaction more similar to that of $\mathrm{C}_{3}$ and CAM plants than to that of $\mathrm{C}_{4}$ species.

Given the limited and conflicting nature of information regarding the existence of $\mathrm{C}_{4}$-CAM intermediates, it was the purpose of the present study to examine the photosynthetic pathway(s), under wellwatered and drought-stressed conditions, of three annual species of $\mathrm{C}_{4}$ succulents in the genus Portulaca: $P$. oleracea, a cosmopolitan weed that grows best in freshly disturbed soil (Matthews et al. 1993); P. mun$d u l a$, a small succulent native to the central and southwestern United States that grows in shallow, gravelly soil over limestone outcrops (Matthews and Levins $1985 a, 1985 b)$; and $P$. grandiflora, an ornamental cultivar, which grows best in sandy soil, originally from northern South America (Bailey and Bailey 1976). Based on anatomical (Welkie and Caldwell 1970; A. A. Kraybill, personal observation) and physiological characteristics (Tregunna and Downton 1967; Martin et al. $1982 ; \mathrm{d}^{13} \mathrm{C}$ of $P$. mundula $=-13.8 \%$, unpublished data), these three species of Portulaca are clearly $\mathrm{C}_{4}$ plants. A further objective was to determine whether the presence or degree of CAM is correlated with the potential aridity of the typical habitat of each species.

\section{Material and methods}

\section{Plant COllection AND CUltivation}

Plants of Portulaca oleracea L. were collected from a recently cultivated ornamental plot on the campus of the University of Kansas, Lawrence, Kansas. The plants were growing in full sun and well-drained topsoil. Mature plants of Portulaca grandiflora Hook were purchased locally. Seedlings of Portulaca mundula I. M. Johnst. were collected from thin pasture soil over limestone outcrops ca. $6.5 \mathrm{~km}$ southwest of Neodesha, Wilson County, Kansas.

Plants were potted in a $1: 2(\mathrm{v} / \mathrm{v})$ mixture of sand and standard greenhouse soil $(7: 2: 2: 1[\mathrm{v} / \mathrm{v}]$ mixture of clay loam, peat moss, Perlite, and vermiculite) and were grown in the greenhouse under the following conditions: average maximum PPFD of $1000 \mu \mathrm{mol} \mathrm{m} \mathrm{m}^{-2} \mathrm{~s}^{-1}$, daytime temperature range of $27^{\circ}-36^{\circ} \mathrm{C}$, nighttime temperature range of $15^{\circ}-$ $26^{\circ} \mathrm{C}$, daily watering, and weekly fertilization (solution of $18 \%$ of each of total $\mathrm{N}, \mathrm{P}_{2} \mathrm{O}_{5}, \mathrm{~K}_{2} \mathrm{O}$; including trace elements). The approximate nighttime vapor pressure deficit (vpd) was $0.3-1.0 \mathrm{kPa}$, while the daytime vpd was ca. 1.8 $3.6 \mathrm{kPa}$. Drought-stressed individuals of $P$. grandiflora and $P$. oleracea received no water for $4 \mathrm{~d}$ prior to gas exchange analysis; $P$. mundula plants received no water for $11 \mathrm{~d}$ prior to experimentation. A reduction in the midday plant water potential was used as a preliminary indicator of drought stress. The xylem water potential of the well-watered plants of the three species was approximately $-0.3 \mathrm{MPa}$. Water was withheld until plants exhibited a xylem water potential of -0.6 to $-0.8 \mathrm{MPa}$, as determined by Scholander pressure chamber measurements of shoot xylem tension.

\section{GAS EXCHANGE}

$\mathrm{CO}_{2}$ and water vapor exchange were measured with an open, differential infrared gas analysis system (Harris and Martin 1991; Gravatt and Martin 1992). Intact shoots were sealed in gas exchange cuvettes for $2 \mathrm{~d}$; soil and roots remained outside the cuvettes. Environmental conditions inside the cuvettes were: PPFD at plant height of $1000 \mu \mathrm{mol}$ $\mathrm{m}^{-2} \mathrm{~s}^{-1}, 30^{\circ} / 20^{\circ} \mathrm{C}$ day/night temperatures, and $2.4 / 0.5 \mathrm{kPa}$ day/night leaf to air vpd. During well-watered treatments, the plants received water throughout the measurement period. Due to leaf morphology, an accurate measurement of leaf surface area was impossible to obtain from these plants. Leaf dry weight, however, was obtained and used as an indirect measure of area. Thus, all data are expressed on a dry weight basis. On the second day of gas exchange measurements, shoot tissue was removed from the cuvettes immediately prior to the final dark period. The plant tissue was frozen at $-65^{\circ} \mathrm{C}$ upon sampling until subsequent malate analysis. The remaining shoot tissue was removed and frozen at the end of the dark period.

\section{MALATE ANALYSIS}

Leaf and stem tissue was sliced upon thawing, and cell sap (up to $10 \%$ of total tissue liquid) was extracted by centrifugation (Smith and Lüttge 1985). Malate concentrations of the sap were determined using the enzymatic/spectrophotometric method of Gutmann and Wahlefeld (1974) and a standard curve based upon known malate concentrations. As the $\mathrm{pH}$ of the buffer used in this assay is quite high, most malic acid is converted to malate upon analysis. Thus, tissue malic acid concentration will be discussed, as it is more technically correct, though tissue malate concentrations were actually measured.

\section{STATISTICS}

The nonparametric Mann-Whitney $U$-test was used to compare two means. Low sample sizes made the normality of the data distribution difficult to determine, thus preventing the use of parametric statistics.

\section{Results}

\section{WELL-WATERED PLANTS}

Uptake of $\mathrm{CO}_{2}$ was observed only during the day in all three species (figs. 1-3); no net uptake occurred at night. Daytime internal $\mathrm{CO}_{2}$ concentrations were lowest and $\mathrm{CO}_{2}$ uptake rates highest in Portulaca oleracea, followed by Portulaca grandiflora and Portulaca mundula. Stomatal conductance patterns of $P$. grandiflora matched assimilation; values were higher during the day and lower at night. In contrast, conductances for $P$. mundula were higher at night than during the day but were not accompanied by nighttime $\mathrm{CO}_{2}$ assimilation. This phenomenon also was observed in $P$. oleracea during the second day/night period.

The amount of $\mathrm{CO}_{2}$ assimilated throughout the day 

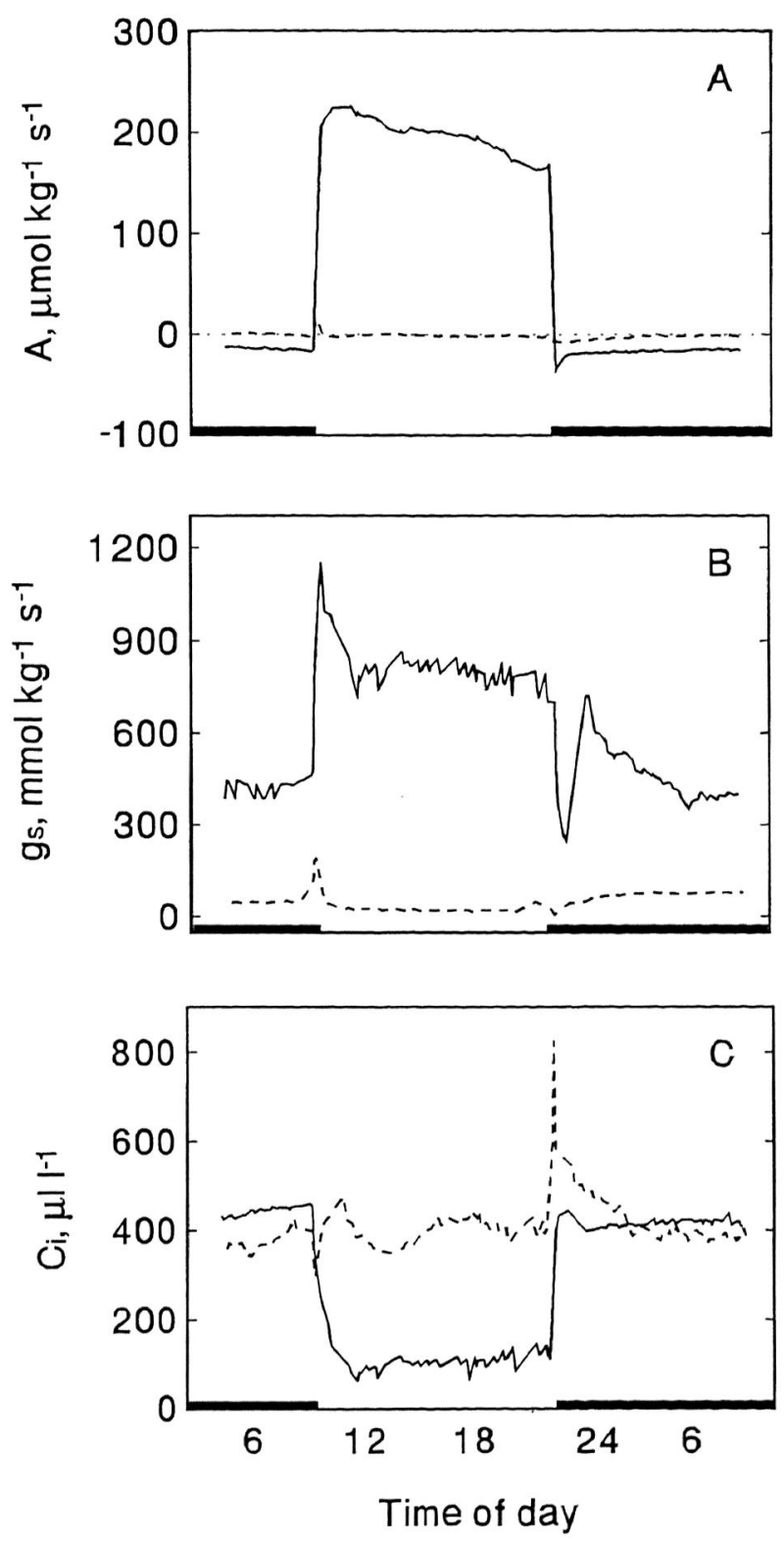

Fig. 1 Diurnal patterns of net $\mathrm{CO}_{2}$ assimilation (A, fig. $1 A$ ), stomatal conductance $\left(g_{s}\right.$, fig. $1 B$ ), and leaf internal $\mathrm{CO}_{2}$ concentration $\left(\mathrm{C}_{\mathrm{i}}\right.$, fig. $\left.1 C\right)$ of shoots of Portulaca grandiflora under well-watered conditions (solid line) and drought-stressed conditions (dashed line). Results from the same plants are shown in each graph; mean day and night $\mathrm{CO}_{2}$ exchange of four individuals are given in table 1 . Data are expressed on a dry mass basis. Black bars indicate night.

by $P$. oleracea was over twice that of $P$. grandiflora and more than four times that of $P$. mundula (table 1). Total nighttime release of $\mathrm{CO}_{2}$ was approximately equal in $P$. grandiflora and $P$. oleracea, while less $\mathrm{CO}_{2}$ was released by $P$. mundula. Total integrated water use efficiency (WUE) was more positive in $P$. oleracea than in $P$. mundula and $P$. grandiflora (table 2 ).

Morning and evening tissue malic acid concentrations were not significantly different in leaves of the species under well-watered conditions (fig. 4) and in stems of $P$. grandiflora and $P$. mundula (fig. 5). Due to sampling difficulties, malic acid fluctuations were not measured in stems of well-watered $P$. oleracea.
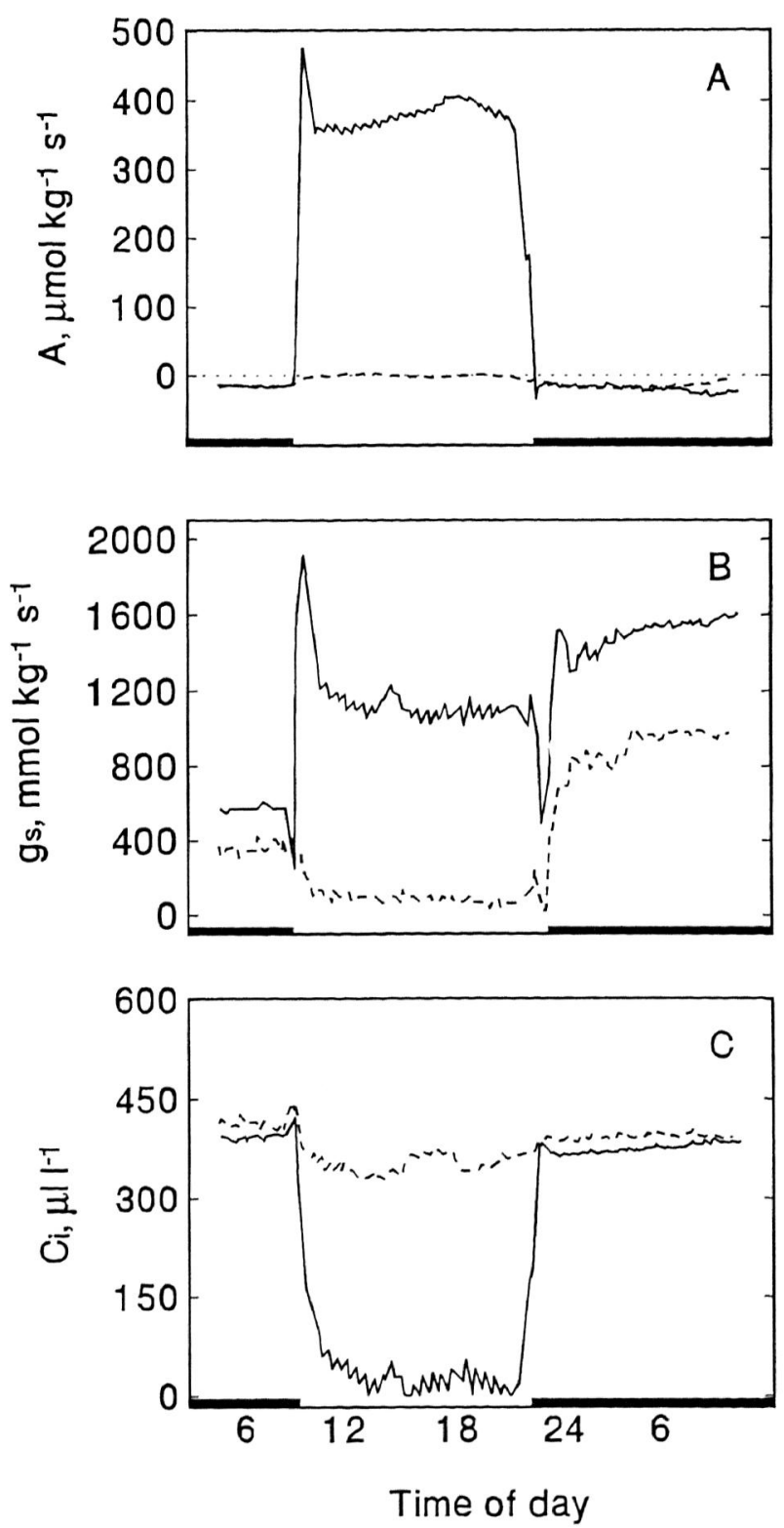

Fig. 2 Diurnal patterns of net $\mathrm{CO}_{2}$ assimilation (A, fig. $2 A$ ), stomatal conductance $\left(\mathrm{g}_{s}\right.$, fig. $2 B$ ), and leaf internal $\mathrm{CO}_{2}$ concentration $\left(\mathrm{C}_{\mathrm{i}}\right.$, fig. $2 \mathrm{C}$ ) of shoots of Portulaca oleracea under well-watered conditions (solid line) and drought-stressed conditions (dashed line). Results obtained as in fig. 1.

\section{DROUGHT-STRESSED PLANTS}

Significant daytime $\mathrm{CO}_{2}$ uptake was not detected in $P$. grandiflora under drought stress (fig. 1a). Likewise, drought-stressed individuals of $P$. oleracea exhibited only small amounts of net daytime $\mathrm{CO}_{2}$ assimilation; no nighttime uptake was observed (fig. $2 a$ ). Relatively high rates of $\mathrm{CO}_{2}$ assimilation, though generally lower than control rates, occurred during the day in all individuals of $P$. mundula, while net nocturnal $\mathrm{CO}_{2}$ uptake was observed only in one plant (fig. $3 a$ ). The three species of Portulaca exhibited reduced nocturnal rates of respiration relative to well-watered plants (table 1$)$.

Nocturnal stomatal conductances for $P$. oleracea were greater than daytime values, with higher conductances measured during the second than the first night 

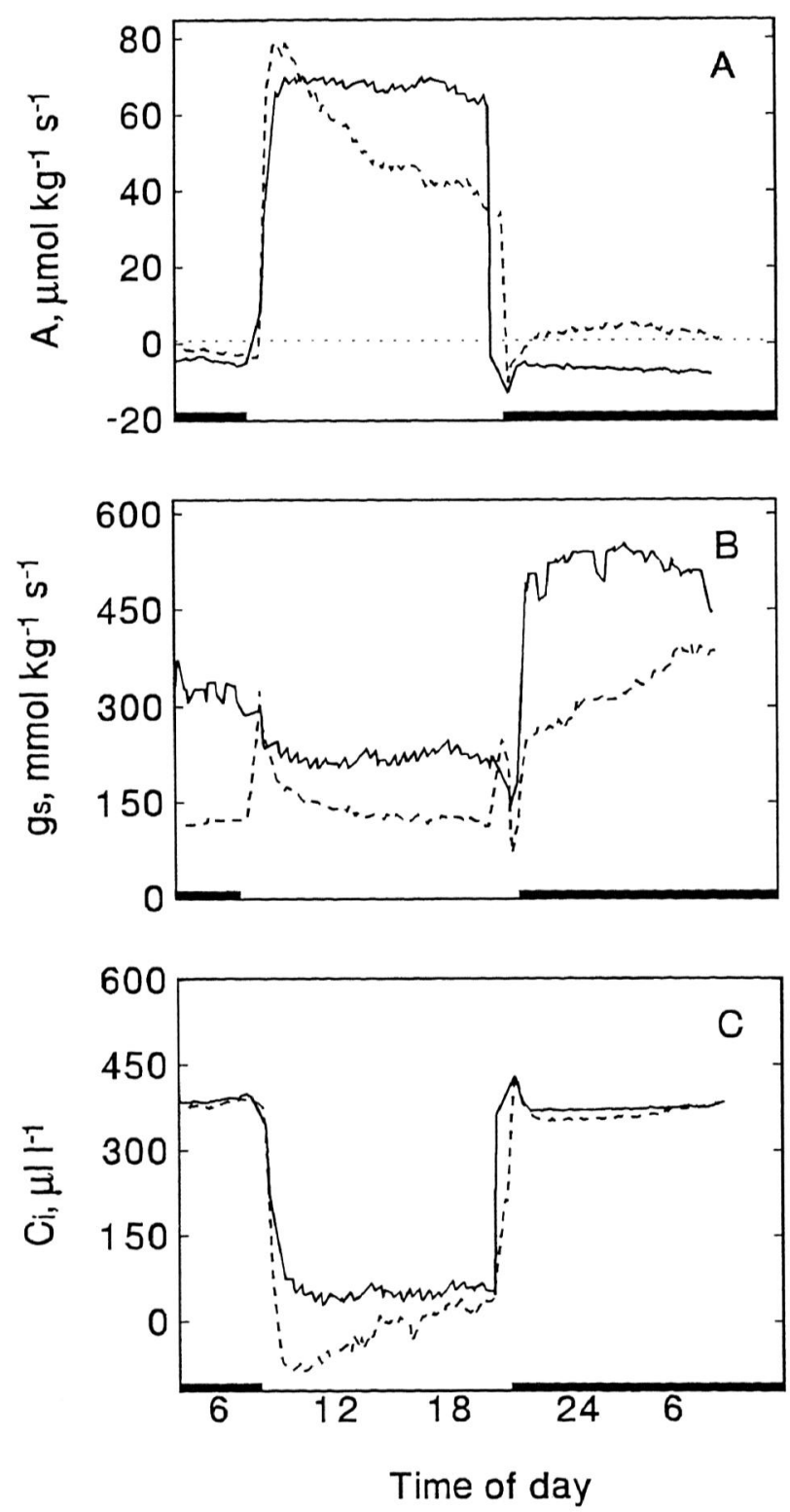

Fig. 3 Diurnal patterns of net $\mathrm{CO}_{2}$ assimilation (A, fig. $3 A$ ), stomatal conductance $\left(g_{s}\right.$, fig. $3 B$ ), and leaf internal $\mathrm{CO}_{2}$ concentration $\left(\mathrm{C}_{\mathrm{i}}\right.$, fig. $\left.3 \mathrm{C}\right)$ of shoots of Portulaca mundula under well-watered conditions (solid line) and drought-stressed conditions (dashed line). Results obtained as in fig. 1. Note: negative $\mathrm{C}_{\mathrm{i}}$ values resulted from instrument limitations in measuring extremely low conductances concomitant with high rates of $\mathrm{CO}_{2}$ uptake.

(fig. 2b). In addition, conductances observed in $P$. oleracea during both light and dark periods were higher than in the other species. Conductances for shoots of $P$. mundula were similar during the first day and night but increased during the second night (fig. $3 b$ ). The stomatal conductance of $P$. grandiflora was lower than that of the other species and changed little throughout the measurement period (fig. $1 b$ ).

The total integrated WUE of $P$. mundula was similar under drought-stressed conditions and under wellwatered conditions (table 2). Portulaca grandiflora and $P$. oleracea, however, exhibited no net $\mathrm{CO}_{2}$ uptake under drought-stressed conditions, therefore WUE was not calculated.

Morning and evening leaf malic acid concentrations were significantly different in all species under drought-stressed conditions (fig. 4). Diurnal malic acid fluctuations were greater in leaves of $P$. mundula and $P$. grandiflora than in $P$. oleracea. Low sample sizes made statistical interpretation of stem malic acid fluctuations difficult. Diurnal changes did occur, however, and the magnitude of the acid fluctuations for individuals of $P$. oleracea was generally higher than that of the other two species (fig. 5).

\section{Discussion}

While there were no significant differences in shoot water content between well-watered and droughtstressed plants in the current study (data not shown), other indications of drought stress were clearly evident. Plant midday water potentials were ca. $-0.3 \mathrm{MPa}$ under well-watered conditions, but were reduced by 0.3-0.6 MPa under drought stress conditions (data not shown), and daytime assimilation rates were reduced in all three species. Finally, under drought stress, significant diurnal malic acid fluctuations, which did not occur in well-watered plants, were observed in all species.

Carbon dioxide exchange patterns for the three species under well-watered conditions were similar to other $\mathrm{C}_{4}$ species, though rates were lower; $\mathrm{CO}_{2}$ was taken up during the day and released at night. Under drought stress, gas exchange patterns were similar to those of well-watered individuals, albeit at reduced levels. Net nocturnal $\mathrm{CO}_{2}$ assimilation did occur in a few individuals, however. Comparable $\mathrm{CO}_{2}$ exchange patterns in Portulaca oleracea under drought stress were reported by Koch and Kennedy (1980, 1982).

Diurnal stomatal conductance patterns in well-watered individuals of Portulaca mundula were unlike those found in the other species; conductances were lower during the day than during the night. Higher nighttime conductances were observed despite high calculated leaf internal $\mathrm{CO}_{2}$ concentrations and were generally not accompanied by $\mathrm{CO}_{2}$ uptake. An explanation for these unusual findings is not available.

Significant diurnal fluctuations of malic acid occurred in the leaves of the three species of Portulaca under drought-stressed conditions. A similar trend was observed in the stem tissue, though low sample sizes made the statistical significance of the measurements questionable. The data is of interest, however, given the scarcity of stem CAM data in leaf succulents. While malic acid fluctuations in $P$. oleracea and Portulaca grandiflora had been documented in past studies, this observation marked the first report of CAM activity in the $\mathrm{C}_{4}$ species $P$. mundula. In addition, the magnitude of the stem and leaf malic acid fluctuations in $P$. oleracea and $P$. grandiflora differed markedly from past findings. Koch and Kennedy $(1980,1982)$ found greater malic acid fluctuations in the leaves than in the stems of droughtstressed $P$. oleracea. In our study, diurnal fluctuations of malic acid in the leaves of drought-stressed $P$. oleracea were comparable to those observed by Koch 
Table 1

INTEGRATED DAY AND Night $\mathrm{CO}_{2}$ EXCHANGE OF WELL-WATERED AND DROUGHT-STRESSED PORTULACA GRANDIFLORA, Portulaca oleracea, and Portulaca mundula

\begin{tabular}{|c|c|c|c|c|c|c|}
\hline \multirow[b]{2}{*}{ Species and treatment } & \multicolumn{3}{|c|}{ Daytime $\mathrm{CO}_{2}$ exchange $\left(\mathrm{mmol} \mathrm{kg} \mathrm{kg}^{-1}\right)$} & \multicolumn{3}{|c|}{ Nighttime $\mathrm{CO}_{2}$ exchange $\left(\mathrm{mmol} \mathrm{kg}{ }^{-1}\right)$} \\
\hline & Uptake & Loss & Net $^{\mathrm{a}}$ & Uptake & Loss & Net $^{\mathrm{a}}$ \\
\hline \multicolumn{7}{|l|}{ P. grandiflora: } \\
\hline Well-watered ............. & $7330(2910)$ & 0 & $7330(2910)$ & 0 & $1013(425)$ & $-1013(425)$ \\
\hline No water for $4 \mathrm{~d} \ldots \ldots \ldots$ & $6 \quad(12)$ & $161(162)$ & $-155(170)$ & $10(20)$ & $310(388)$ & $-301(398)$ \\
\hline \multicolumn{7}{|l|}{ P. oleracea: } \\
\hline Well-watered ............. & $17,635(4033)$ & 0 & $17,635(4033)$ & 0 & $864(156)$ & $-864(156)$ \\
\hline No water for $4 \mathrm{~d} \ldots \ldots \ldots$ & $37 \quad(31)$ & $-145 \quad(76)$ & $-109 \quad(47)$ & 0 & $356(192)$ & $-356(192)$ \\
\hline \multicolumn{7}{|l|}{ P. mundula: } \\
\hline Well-watered $\ldots \ldots \ldots \ldots \ldots$ & $3631 \quad(526)$ & 0 & $3631 \quad(526)$ & 0 & 320 (49) & $-320(49)$ \\
\hline No water for $11 \mathrm{~d} \ldots \ldots \ldots$ & $1816 \quad(558)$ & 0 & $1816(558)$ & $41(69)$ & $47 \quad(23)$ & $-6(88)$ \\
\hline
\end{tabular}

Note. Values are means (standard deviations in parentheses) of four plants and were derived from gas exchange analyses; representative diurnal gas exchange patterns are provided in figures 1-3. Data are expressed on a dry mass basis.

Positive values indicate net $\mathrm{CO}_{2}$ uptake; negative values indicate net $\mathrm{CO}_{2}$ loss.

and Kennedy (1980), but stem acid fluctuations were much higher than previously reported (comparisons made on fresh weight basis, data not shown). In addition, fluctuations of malic acid in both stems and leaves of $P$. grandiflora were much higher than previously reported by $\mathrm{Ku}$ et al. (1981; also compared on fresh weight basis). Finally, both $\mathrm{Ku}$ et al. (1981) and Koch and Kennedy (1980) reported that drought stress reduced the magnitude of diurnal malic acid fluctuations. In our study, however, significant malic acid fluctuations did not occur in well-watered plants while drought stress induced acid fluctuations indicative of CAM. While Martin et al. (1982) found no diurnal acid fluctuations in $P$. oleracea or Portulaca pilosa in the field in North Carolina, the results of our study would indicate that the plants were possibly well-hydrated at the time of measurement.

Though the anatomical and physiological characteristics of the three species of Portulaca in this study indicate $\mathrm{C}_{4}$ photosynthesis (see Introduction), our re-

\section{Table 2}

TOTAL INTEGRATED MOLAR WATER USE EFFICIENCY (WUE) OF WELLWATERED AND DROUGHT-STRESSED PORTULACA GRANDIFLORA, Portulaca oleracea, and Portulaca mundula over THE ENTIRE MEASUREMENT PERIOD

\begin{tabular}{|c|c|}
\hline Species and treatment & $\begin{array}{c}\text { WUE } \\
\left(\mathrm{mmol} \mathrm{CO} 2 / \mathrm{mol} \mathrm{H}_{2} \mathrm{O}\right)\end{array}$ \\
\hline \multicolumn{2}{|l|}{ P. grandiflora: } \\
\hline Well-watered & $4.94(0.46)$ \\
\hline No water for $4 \mathrm{~d} \ldots$ & $\mathrm{na}^{\mathrm{a}}$ \\
\hline \multicolumn{2}{|l|}{ P. oleracea: } \\
\hline Well-watered ..... & $7.01(0.63)$ \\
\hline No water for $4 \mathrm{~d} . . . . .$. & $\mathrm{na}^{\mathrm{a}}$ \\
\hline \multicolumn{2}{|l|}{ P. mundula: } \\
\hline Well-watered ........ & $5.76(1.19)$ \\
\hline No water for $11 \mathrm{~d} \ldots \ldots \ldots \ldots \ldots$ & $5.76(0.53)$ \\
\hline
\end{tabular}

Note. Date are means (standard deviations in parentheses) of four plants.

" na $=$ not available: negative net $\mathrm{CO}_{2}$ exchange prevented calculation of WUE. sults indicate that these plants can also undergo CAM, or at least diurnal acid fluctuations. When nighttime $\mathrm{CO}_{2}$ uptake occurs, the total amount of $\mathrm{CO}_{2}$ fixed is approximately $5 \%-22 \%$ of the total malic acid produced that night. Presumably, the primary source of carbon for nighttime malic acid production is the recycling of respired $\mathrm{CO}_{2}$. This presumption is further supported by a reduction in the amount of $\mathrm{CO}_{2}$ respired by drought-stressed plants at night, relative to well-watered plants of the same species. Respiration rates in drought-stressed individuals of $P$. oleracea, $P$. grandiflora, and $P$. mundula were ca. $40 \%, 30 \%$, and $2 \%$ of the rates of well-watered plants, respectively. In addition, the changes in malic acid concentration in the three species under drought stress closely correlate with the reductions in respiration.

The recycling of respiratory $\mathrm{CO}_{2}$ per se should not directly benefit the plants because energy must be expended to reduce the $\mathrm{CO}_{2}$, regardless of its source (Martin 1995). On the other hand, this process might indirectly benefit the plants. High levels of malic acid in well-watered plants may constitute a pool of malic acid that could be utilized as an alternative source of carbon during drought stress. Nighttime fixation of respiratory $\mathrm{CO}_{2}$ might then replenish malic acid stores without the water loss associated with a high daytime leaf to air vpd. In addition, the recycling of respiratory $\mathrm{CO}_{2}$ would allow for maintenance respiration during severe drought. During the day, the release of additional $\mathrm{CO}_{2}$ from stored malic acid might also prevent stress-induced damage to the photosynthetic apparatus.

If " $\mathrm{C}_{4}$-CAM-cycling" is indeed an adaptation to drought stress, the greatest degree of acid fluctuations might be expected in $P$. mundula, which tends to grow in the most arid habitats. Portulaca mundula did indeed exhibit malic acid fluctuations (stem and leaf) that are higher than those of $P$. oleracea and $P$. grandiflora, which are approximately equal. Also, under drought stress, the highest WUE is observed in $P$. mundula. Finally, a drought period $1 \mathrm{wk}$ longer than that of the two other species is required to effect an 

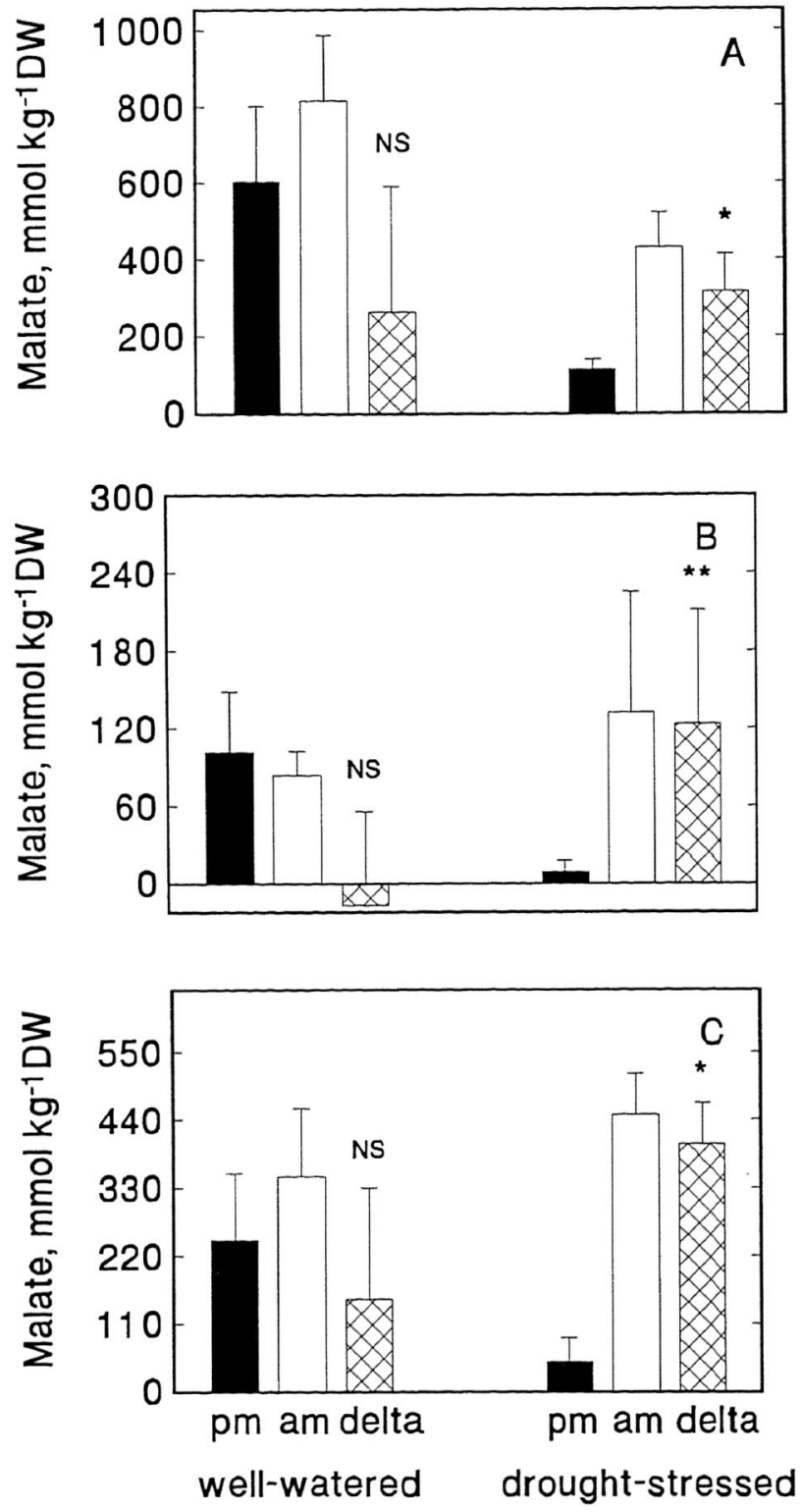

Fig. 4 Morning and evening leaf malic acid concentrations and diurnal malic acid fluctuations (delta) in well-watered and droughtstressed individuals of Portulaca grandiflora (fig. 4A), Portulaca oleracea (fig. 4B), and Portulaca mundula (fig. 4C). Data are expressed on a dry mass basis. Values are means of four plants; error bars represent standard deviations. $N S=$ not significant; $*=P \leq$ $0.05 ; * *=P \leq 0.01$.

appreciable decrease in the shoot water potential of $P$. mundula, and yet $\mathrm{CO}_{2}$ exchange rates are much less affected than those of the other species. Attempts to relate the potential degree of aridity of the habitat of the three species with the magnitude of CAM observed in the laboratory, however, are possibly confounded by greenhouse growth conditions. For example, the degree of CAM may have been greater in all plants when grown under full sunlight and continuous droughtstressed conditions.

In conclusion, this study confirms that some level of CAM can occur in these succulent species of the genus Portulaca. Given the biochemical similarities between CAM and $\mathrm{C}_{4}$ plants, this combination of photosynthetic pathways is not completely unexpected.
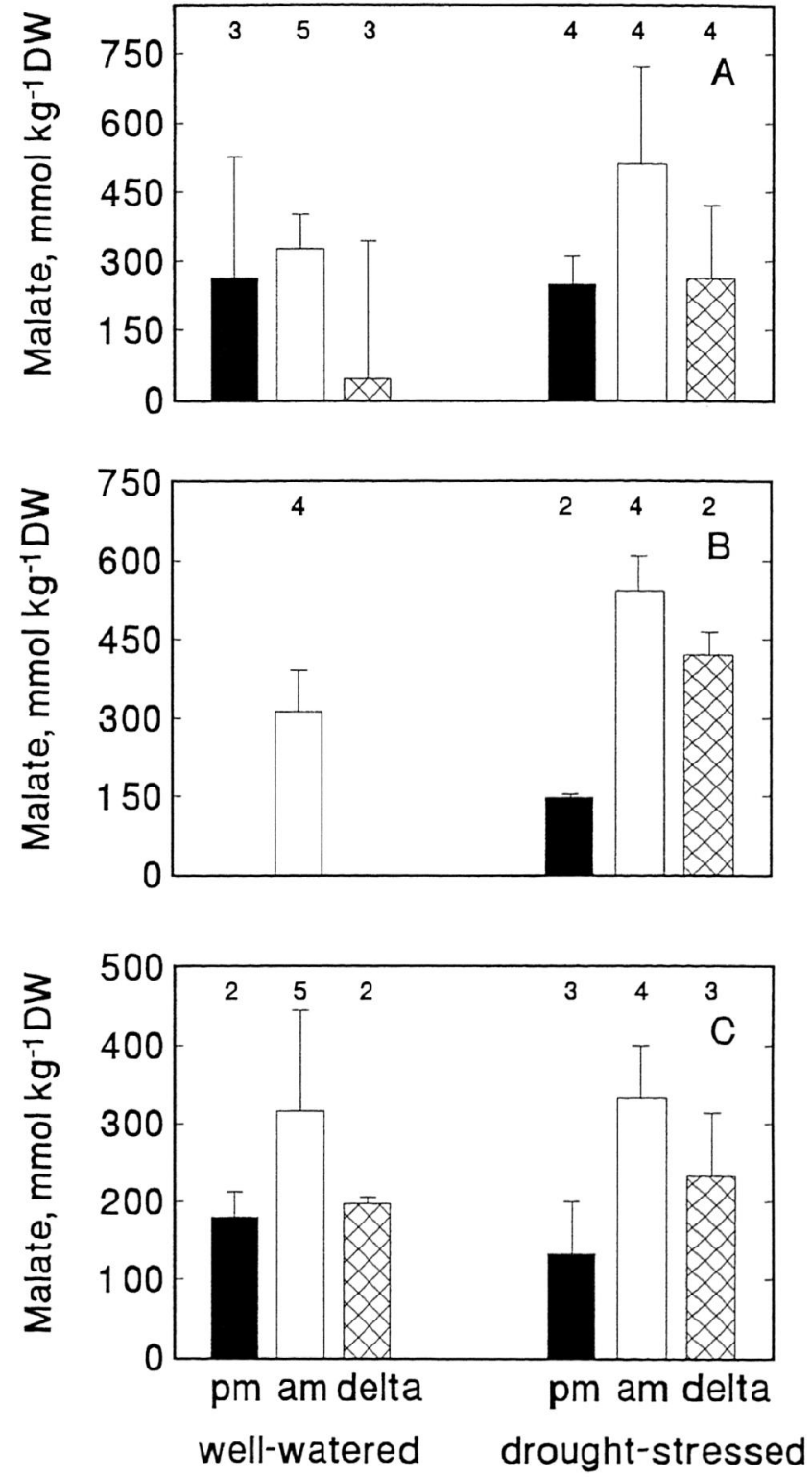

Fig. 5 Morning and evening stem malic acid concentrations and diurnal malic acid fluctuations (delta) in well-watered and droughtstressed individuals of Portulaca grandiflora (fig. 5A), Portulaca oleracea (fig. 5B), and Portulaca mundula (fig. 5C). Data are expressed on a dry mass basis. Sample sizes are noted above each bar; error bars represent standard deviations.

The biochemical regulation of $\mathrm{C}_{4}$ and CAM in the same tissue, however, is not fully understood $(\mathrm{Ku}$ et al. 1981). Also, as this combination of photosynthetic pathways appears to be rare among $C_{4}$ species the question of its ecological significance, if any, remains to be answered. These biochemical and adaptive questions require further investigation before this unusual combination of $\mathrm{C}_{4}$ and CAM can be fully understood.

\section{Acknowledgments}

This study was funded in part by the College of Liberal Arts and Sciences of the University of Kansas. We would like to thank Mr. Maynard Struthers of Neodesha, Kansas, for providing access to his land for specimen collection. 


\section{Literature cited}

Bailey LH, EZ Bailey 1976 Hortus third: a concise dictionary of plants cultivated in the United States and Canada. MacMillan, New York.

Black CC 1973 Photosynthetic carbon fixation in relation to net $\mathrm{CO}_{2}$ uptake. Annu Rev Plant Physiol 24:253-286.

Edwards G, DA Walker $1983 \mathrm{C}_{3}, \mathrm{C}_{4}$ : mechanisms, and cellular and environmental regulation, of photosynthesis. Blackwell, Oxford.

Ehleringer JR, RK Monson 1993 Evolutionary and ecological aspects of photosynthetic pathway variation. Annu Rev Ecol Syst 24:411-439.

Fathi M, C Schnarrenberger 1990 Purification by immunoadsorption and immunochemical properties of NADP-dependent malic enzymes from leaves of $\mathrm{C}_{3}, \mathrm{C}_{4}$, and Crassulacean acid metabolism plants. Plant Physiol 92:710-717.

Gravatt DA, CE Martin 1992 Comparative ecophysiology of five species of Sedum (Crassulaceae) under well-watered and droughtstressed conditions. Oecologia 92:532-541.

Guralnick LJ, MD Jackson 1993 Crassulacean acid metabolism activity in the family Portulacaceae. Plant Physiol 102(suppl):139.

Gutmann I, AW Wahlefeld 1974 L-(-)-malate: determination with malate dehydrogenase and NAD. Pages 1585-1589 in HU Bergmeyer, ed. Methods of enzymatic analysis. Vol 3. 2d English ed. Verlag Chemie, Weinheim.

Harris FS, CE Martin 1991 Correlation between CAM-cycling and photosynthetic gas exchange in five species of Talinum (Portulacaceae). Plant Physiol 96:1118-1124.

Karadge BA 1986 Photosynthetic carbon assimilation in potassium stressed Portulaca oleracea L. Photosynthetica 20:29-34.

Kluge M, IP Ting 1978 Crassulacean acid metabolism: analysis of an ecological adaptation. Springer-Verlag, Berlin.

Koch KE, RA Kennedy 1980 Characteristics of Crassulacean acid metabolism in the succulent $\mathrm{C}_{4}$ dicot, Portulaca oleracea L. Plant Physiol 65:193-197.

1982 Crassulacean acid metabolism in the succulent $\mathrm{C}_{4}$ dicot Portulaca oleracea L. under natural environmental conditions. Plant Physiol 69:757-761.

Ku SB, YJ Shieh, BJ Reger, CC Black 1981 Photosynthetic characteristics of Portulaca grandiflora, a succulent $\mathrm{C}_{4}$ dicot. Plant Physiol 68:1073-1080.

Lüttge U 1993 The role of Crassulacean acid metabolism (CAM) in the adaptation of plants to salinity. New Phytol 125:59-71.

Martin CE 1995 Putative causes and consequences of recycling $\mathrm{CO}_{2}$ via CAM. In $\mathrm{K}$ Winter, JAC Smith, eds. Crassulacean acid metabolism: biochemistry, ecology and evolution. Springer-Verlag, Berlin.

Martin CE, M Higley, W-Z Wang 1988 Ecophysiological signifi- cance of $\mathrm{CO}_{2}$-recycling via Crassulacean acid metabolism in $\mathrm{Ta}$ linum calycinum Engelm. (Portulacaceae). Plant Physiol 86:562568.

Martin CE, AE Lubbers, JA Teeri 1982 Variability in Crassulacean acid metabolism: a survey of North Carolina succulents. Bot Gaz 143:491-497.

Matthews JF, DW Ketron, SF Zane 1993 The biology and taxonomy of the Portulaca oleracea L. (Portulacaceae) complex in North America. Rhodora 95:166-183.

Matthews JF, PA Levins $1985 a$ The genus Portulaca in the southeastern United States. Castanea 50:96-104.

— $1985 b$ Portulaca pilosa L., P. mundula I. M. Johnst. and P. parvula Gray in the Southwest. Sida Contrib Bot 11:45-61.

Osmond CB 1982 Carbon cycling and stability of the photosynthetic apparatus in CAM. Pages $112-127$ in IP Ting, M Gibbs, eds. Crassulacean acid metabolism. American Society of Plant Physiologists, Rockville, Md.

Osmond CB, K Winter, SB Powles 1980 Adaptive significance of carbon dioxide cycling during photosynthesis in water-stressed plants. Pages 139-154 in NC Turner, PJ Kramer, eds. Adaptations of plants to water and high temperature stress. Wiley, New York.

Osmond CB, K Winter, H Ziegler 1982 Functional significance of different pathways of $\mathrm{CO}_{2}$ fixation in photosynthesis. Pages 479547 in OL Lange, PS Nobel, CB Osmond, H Ziegler, eds. Physiological plant ecology. Vol 2, Water relations and carbon assimilation. Encyclopedia of plant physiology, ns, vol 12, pt B. Springer-Verlag, Berlin.

Rayder L, IP Ting 1981 Carbon metabolism in two species of $P e$ reskia (Cactaceae). Plant Physiol 68:139-142.

Sipes DL, IP Ting 1985 Crassulacean acid metabolism and Crassulacean acid metabolism modifications in Peperomia camptotricha. Plant Physiol 77:59-63.

Smith JAC, U Lüttge 1985 Day-night changes in leaf water relations associated with the rhythm of Crassulacean acid metabolism in Kalanchoë daigremontiana. Planta 163:272-282.

Ting IP 1985 Crassulacean acid metabolism. Annu Rev Plant Physiol 36:595-622.

Tregunna EB, J Downton 1967 Carbon dioxide compensation in members of the Amaranthaceae and some related families. Can J Bot 45:2385-2387.

Welkie GW, M Caldwell 1970 Leaf anatomy of species in some dicotyledon families as related to the $\mathrm{C}_{3}$ and $\mathrm{C}_{4}$ pathways of carbon fixation. Can J Bot 48:2135-2146.

Winter K 1985 Crassulacean acid metabolism. Pages 329-381 in J Barber, NR Baker, eds. Photosynthetic mechanisms and the environment. Elsevier, Amsterdam. 